\title{
SOME DATA ON THE BEHAVIOUR OF KITES (MILVUS MILVUS, MILVUS MIGRANS) NESTING CLOSE TO TWO ACTIVE WIND FARMS IN SAXONY, GERMANY
}

\author{
Przemysław Busse and Izabella Rząd
}

\begin{abstract}
Busse P., Rząd I. 2017. Some data on the behaviour of kites (Milvus milvus, Milvus migrans) nesting close to two active wind farms in Saxony, Germany. Ring 39: 121-136.

The main aim of this study was to evaluate how local pairs of kites behave in the vicinity of two wind farms located in the same region (Saxony, Germany) and at farms which are to be re-powered. We observed three pairs that had located their nests close to active wind farms (a few hundred to $1500 \mathrm{~m}$ from the wind farm). Special attention was focused on variation in the intensity of flights and its dependence on the local landscape and to active avoidance of existing wind turbines. Observations were made at the end of the breeding time, when the young were still in the nest and shortly after fledging. Despite the short observation periods, the results seem to show clearly how differentiated the flight patterns of these birds are in relation to the landscape features around the farm. The distance from the nest to the wind farm cannot be the only measure of the level of potential wind-farmrelated danger to the birds nesting close to the farm site.

Distribution of flights is not random, but clearly concentrated on defined target hunting areas, while other directions are visited infrequently. In the case of both farms, the farm was rarely crossed by the Black Kites (9.9\% of all flights) and very rarely (2.8\%) by the Red Kites, and such crossing was observed only while the turbine rotors were not in motion or when the rotors were turning slowly (below 5 turns/min.). It may be advisable to conduct special monitoring of movement patterns at breeding time if kite nests are found close to the planned location of the wind farm.
\end{abstract}

P. Busse, Bird Migration Research Foundation, Przebendowo, 84-210 Choczewo, Poland, E-mail: busse@wbwp-fund.eu; I. Rząd, Department of Ecology and Environmental Protection, Faculty of Biology, Institute for Research on Biodiversity, University of Szczecin, ul. Wąska 13, 71-415 Szczecin, Poland

Keywords: Milvus, kites, wind farms, breeding, behaviour, Saxony

\section{INTRODUCTION}

It is well known among experts monitoring wind farm sites, before and after their construction, that despite general rules governing avian species behaviour during the 
breeding season, there are also exceptions caused by local constraints in a given area, e.g. landforms, dominant habitat, and human influences such as villages, industrial areas and roads. All of these cause breeding sites, feeding areas, and the routes and height of local movements to be selected on a local scale. Hence a number of local factors may change the probability of collision for birds, complicating estimation of the actual impact of a wind farm on local birds. A standard practice is to assess the potential influence of a planned wind farm according to pre-construction monitoring and evaluation of collected data. The methods used are highly varied, and the experts' conclusions range from general statements such as, 'many interesting birds were observed during breeding time/migration, so this is an unsuitable location for the wind farm', to more detailed descriptions, including the location of actual nests of birds of conservation concern, and the use of 'acceptable distances' between a nest and the wind farm (e.g. LAG VSW 2014), to evaluation of collision risk using various sophisticated models (e.g. Smales 2006, Band et al. 2007, Percival 2007, Scottish Natural Heritage 2011, Eichhorn 2012, Busse 2013). Data collection for assessment decisions is most sophisticated and exact when technically advanced methods are used, such as GPS tracking of the birds of concern. However, all pre-construction monitoring methods, while they may include the behavioural aspect of collisions (avoidance indices in modelling), are applied to a situation where the birds are not actually confronted with the working wind turbines. Thus birds behave differently than when they live close to an actual wind farm. Observations of birds' behaviour after the farm has been built and comparisons with pre-construction monitoring remain scarce. A very interesting example was recently presented during the 2017 meeting of EOU in Turku, Finland (Schaub et al. 2017). Additionally, the authors cited used the most exact GPS tracking of the harriers observed.

The aim of this study was to evaluate how local pairs of kites behave in the vicinity of wind farms that are to be re-powered. Special attention was given to variation in flight intensity depending on the local landscape, as well to active avoidance of existing wind turbines.

\section{THE STUDY AREA}

The Mutzschen wind farm (Saxony, Germany) is now powered with 8 turbines of $2 \mathrm{MW}$ (rotor $90 \mathrm{~m}$, tower $105 \mathrm{~m}$ ). It is to be re-powered with two turbines of $3.6 \mathrm{MW}$ (rotor $130 \mathrm{~m}$, tower $85 \mathrm{~m}$ ) plus two turbines of $2 \mathrm{MW}$ (rotor $100 \mathrm{~m}$, tower $80 \mathrm{~m}$ ) and one turbine of $3.5 \mathrm{MW}$ (rotor $101 \mathrm{~m}$, tower $74 \mathrm{~m}$ ).

The area studied is a typical habitat for Red Kite - open farmland with patches of trees and dispersed small villages, connected by narrow local routes, partly framed by trees. South of the wind farm there is a highway with heavy traffic and a lot of noise. The shortest distance from a known Red Kite nest to the highway is around $1,200 \mathrm{~m}$ (Map 1). The larger town of Nerchau with some industrial infrastructure is located at a distance of slightly over $3 \mathrm{~km}$. Most of the area around the nest, the wind farm and the motorway is covered by fairly large fields with varied crops, mainly rapeseed, wheat and maize, with some sugar beet and meadows. It should be added that in some of the wheat fields the plants were lying flat as a result of earlier heavy rains and storms, which altered the normal appearance and character of the habitat. 


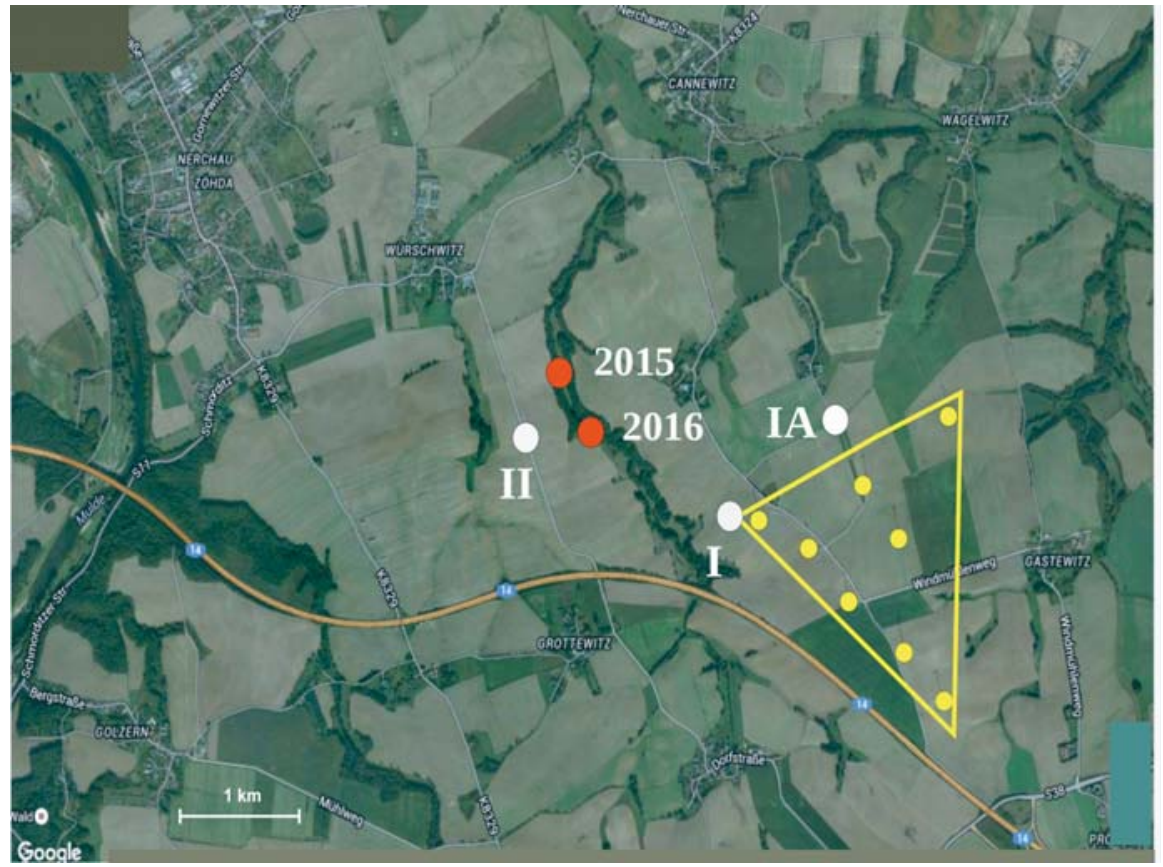

Map 1. The area of the study at Mutzschen. White circles (I, IA, II) - locations of observation stands, red circles - locations of the Red Kite nests in 2015 and 2016, yellow circles location of turbines, yellow triangle - the wind farm area.

The problem to be studied at Mutzschen was the safety of a Red Kite pair breeding in the vicinity of the farm. In 2015 the distance from the nest to the working farm was about 1,400 m, while for breeding in 2016 these birds situated their nest closer the farm, at a distance of about 1,200 m (Map 1). These distances are close to the generally accepted distances between Red Kite nests and wind farms (LAG VSW 2014).

The second wind farm area studied, Mautitz, lies about 20 kilometres from the first and is currently powered by four turbines of $3.0 \mathrm{MW}$ (rotor $101 \mathrm{~m}$, tower $135 \mathrm{~m}$ ). It is to be enlarged by building an additional 8 turbines - four of $3.45 \mathrm{MW}$ (rotor $112 \mathrm{~m}$, tower $140 \mathrm{~m}$ ) and four of $3.45 \mathrm{MW}$ (rotor $126 \mathrm{~m}$, tower $149 \mathrm{~m}$ ).

The Mautitz wind farm is surrounded by a few smaller settlements - Mautitz, Groptitz, Ragewitz, Grubnitz, Blosswitz, Reppen and Ganzing (at distances below $3 \mathrm{~km}$ ). The larger town of Riesa lies at a distance of slightly over $4 \mathrm{~km}$. Most of the area around the nests, the wind farm and the road is covered by fairly large fields with varied crops - mainly rapeseed, wheat and maize. It should be added that at the time of the observations a few barley fields had already been harvested and followed by preliminary shallow ploughing, while most of the rape fields had just been mowed and mowing of the wheat fields began in the last two days of the observation time.

Both kite nests are located within a patch of high trees situated close to the road, around $300 \mathrm{~m}$ apart. 
The problem to be studied at Mautitz was the safety of Red Kite and Black Kite pairs breeding in the close vicinity of the farm: in 2016 distance from the nests to the working farm was well below $1000 \mathrm{~m}$. This distance is below the limit of generally accepted distances from wind farms for both Red Kite and Black Kite nests (LAG VSW 2014).

\section{FIELD WORK}

Until fledglings of raptor birds reach full independence, their movements are guided by their parents according to local hunting customs, mainly within the preserve (breeding territory). Thus the behaviour of the family just after the young birds leave the nest follows from the experience of the adults during the chick-feeding period. It is reasonable to combine observations from the breeding and early postbreeding time to draw common conclusions.

Stationary observations were made from three observation posts at the site (for Mutzschen see Map 1 - I, IA and II; for Mautitz see Map 2 - I, II and III) from which the whole area around the nests and the wind farms was covered. Observations were performed simultaneously by two observers from the same post, so that all surrounding terrain $\left(360^{\circ}\right)$ was under continuous control.

The individuals, when 'caught' by the naked eye or binoculars (10x50), were followed as far as possible and then their tracks were drawn on a background map (example for Mutzschen - see Map 3, for Mautitz - see Map 4), and the time of the observation was noted. The tracks ('observation items') were classified as 'circling', 'transport flights',

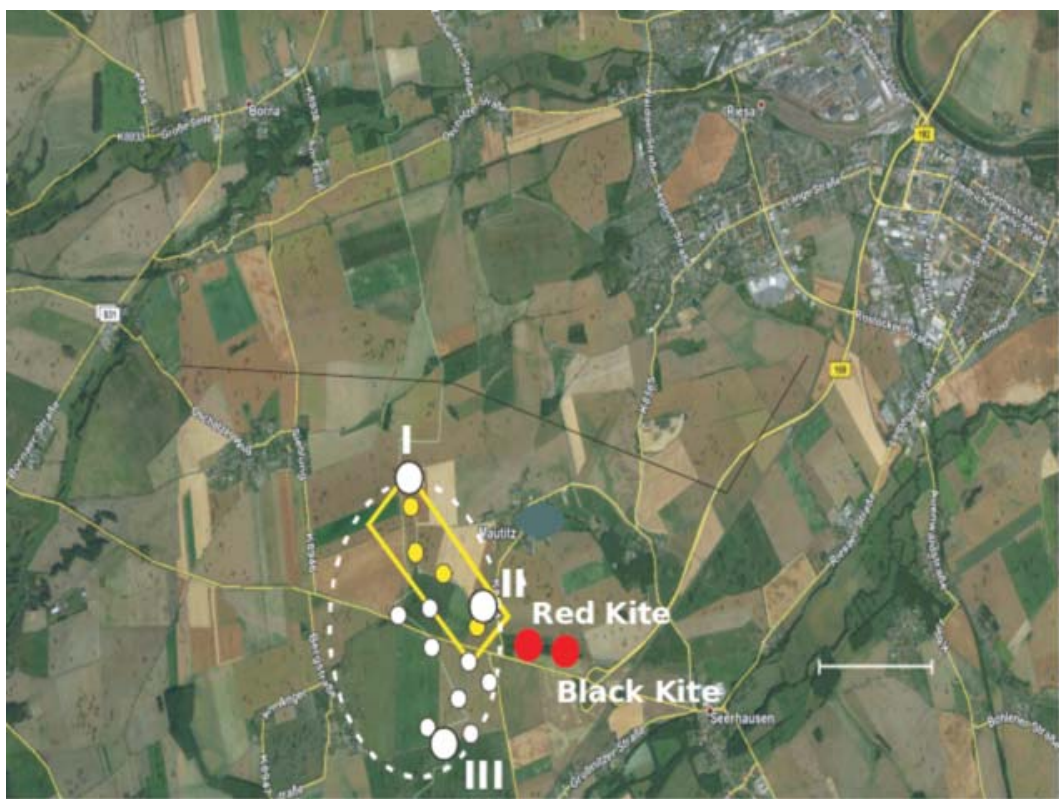

Map 2. The area of the study at Mautitz. White circles - locations of observation stands (I, II, III), red circles - locations of the Red Kite and Black Kite nests in 2016, yellow circles location of active turbines, small white circles - planned turbines, rectangle - the current wind farm area, while ellipse - planned wind farm area. 


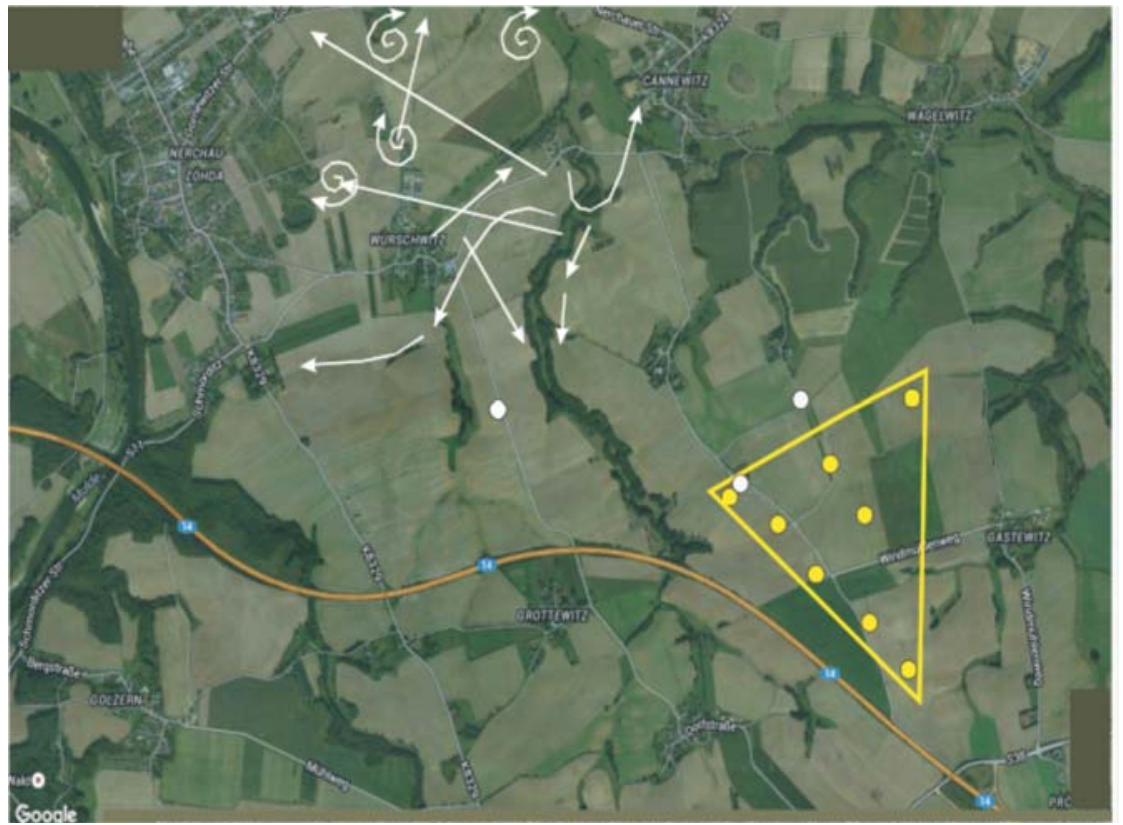

Map 3. Tracks of the kites during one day of observations (example for Mutzschen). White dots observation stands, yellow dots - turbines. Circling locations and flight directions are shown.

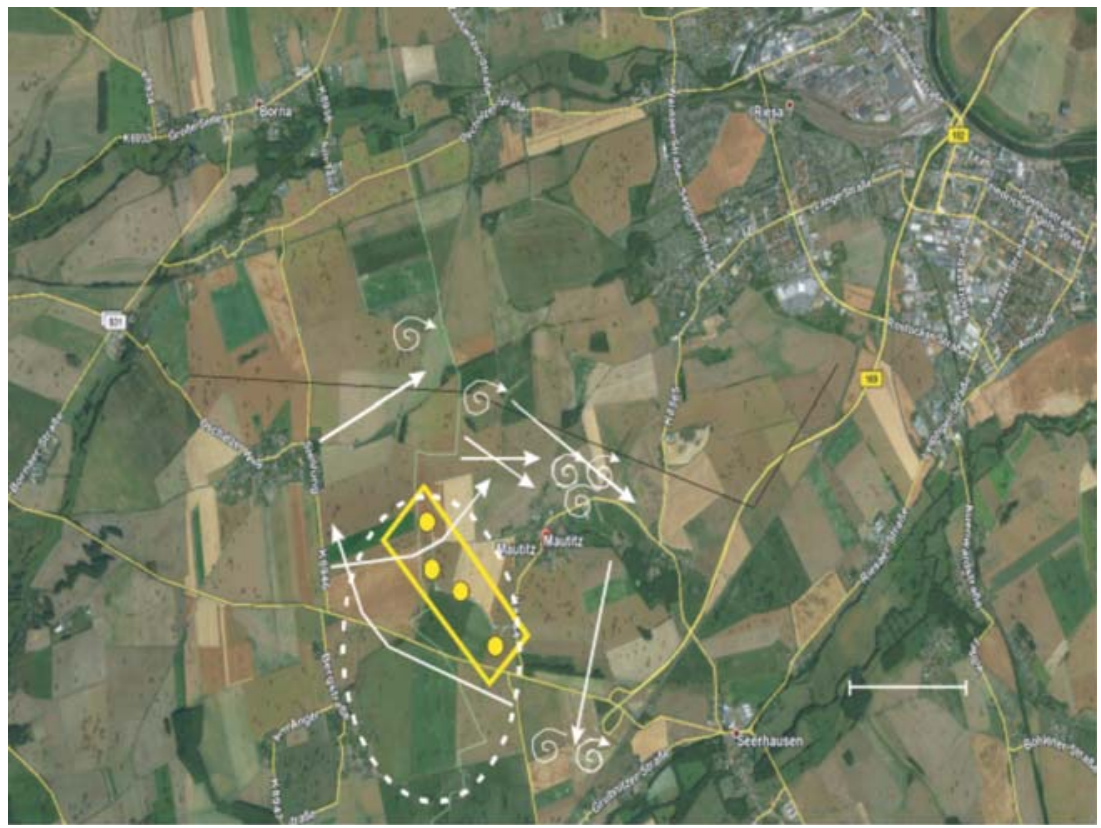

Map 4. Tracks of the kites during one day of observations (example for Mautitz). White dots observation stands, yellow dots/rectangle - current wind farm, ellipse - planned wind farm area. Circling locations and flight directions are shown. 
'sitting on the ground' (attacking prey?) or sitting in a tree or on a utility pole (these last two cases were sporadic). When both birds of the pair in Mutzschen were caught simultaneously, each bird was followed by one of the observers. When possible, we followed the bird by car and tried to establish its feeding destination. This, however, was rare.

The field study at Mutzschen was carried out for 8 days (13-20 June 2016), while the chicks were still in the Red Kite nest, 9-10 hours daily, starting one hour after sunrise (except on 16 June, when observations were conducted for only 3 hours due to continuous rain during part of the day). Altogether there were 71 hours of observations, performed by two observers. Special attention was given to posts I-IA, from which the wind farm was fully under observation (38 hours of observations), while there were 33 hours of observations at post II. The location was changed every 2-3 hours, starting one day from post I and the next day from post II. Only adult Red Kites having a nest close to the farm were recorded, but twice three adults were observed simultaneously. Other raptor species observed in the area, i.e. Common Buzzard Buteo buteo and Kestrel Falco tinnunculus were not followed.

A summary of the observations is presented in Table 1.

Table 1

Timing of observations at Mutzschen and records of Red Kite individuals

\begin{tabular}{|c|c|c|c|c|}
\hline \multirow{2}{*}{ Date } & \multicolumn{2}{|c|}{ Hours at site } & Total hours & Records \\
\cline { 2 - 5 } & I & II & & \\
\hline 13 Jun. & 4 & 5 & 9 & 21 \\
\hline 14 Jun. & 7 & 3 & 10 & 19 \\
\hline 15 Jun. & 5 & 5 & 10 & 14 \\
\hline 16 Jun. & 5 & 5 & 10 & 19 \\
\hline 17 Jun. & 1 & 2 & 3 & 6 \\
\hline 18 Jun. & 5 & 4 & 9 & 13 \\
\hline 19 Jun. & 6 & 4 & 10 & 7 \\
\hline 20 Jun. & 5 & 5 & 10 & 15 \\
\hline Total & $\mathbf{3 8}$ & $\mathbf{3 3}$ & $\mathbf{7 1}$ & $\mathbf{1 1 4}$ \\
\hline
\end{tabular}

The weather during the observations in Mutzschen was highly varied, with rapidly changing cloud cover (various clouds types from cirrus to altostratus, cumulus, and cumulonimbus clouds with rain and thunderstorms). On most days the wind blew from the west, one day from the south, and at the end of the observation period from north to northwest. There were, however, hours with no wind at all. When the wind was blowing we noted its power by estimating the speed of the turbine rotors (the highest motions were 12-13 turns/minute).

At Mautitz, the field study was carried out for 7 days (18-24 July 2016), 8-10 hours daily (8:00-18:00), but after 17:30 there were no records. Altogether there were 68 hours of observations, performed by two observers. Stationary observations were made from three observation posts (see Map 2 - I, II, III), which covered the entire area around the nests and the wind farm. The locations were changed every 2-3 hours. 
Special attention was placed on posts I and II, from which the wind farm (current and planned area) was fully under observation (36 hours of observations), while only 14 hours were spent at post III, as the first two days of observations showed that the area was rarely visited by birds. Initial observations on $18^{\text {th }}$ and $19^{\text {th }}$ July were more flexible, as we additionally monitored a wider area to learn the birds' behaviour over a larger area, following birds outside the main area by car. Thus these days are treated differently than the others in some respects, for compatibility reasons. During the observations performed at Mautitz, young birds of both kite species were already on wings, flying with adults or as singles. Apart from kites, Marsh Harriers Circus aeruginosus were regularly seen here and this species was included as birds of concern. Buzzards and kestrels were not specially followed.

A summary of the observations is presented in the Table 2.

Table 2

Timing of observations at Mautitz and records of Red Kite individuals

\begin{tabular}{|c|c|c|c|c|c|}
\hline \multirow{2}{*}{ Date } & \multicolumn{3}{|c|}{ Hours at site } & \multirow{2}{*}{ Total hours } & \multirow{2}{*}{ Records } \\
\cline { 2 - 4 } & I & II & III & 8 & 8 \\
\hline 18 Jul. & & & & 10 & 27 \\
\hline 19 Jul. & & & & 10 & 34 \\
\hline 20 Jul. & 2 & 4 & 4 & 10 & 11 \\
\hline 21 Jul. & 6 & 2 & 2 & 10 & 40 \\
\hline 22 Jul. & 6 & 2 & 2 & 10 & 33 \\
\hline 23 Jul. & 2 & 4 & 4 & 10 & 30 \\
\hline 24 Jul. & 4 & 4 & 2 & $\mathbf{6 8}$ & $\mathbf{1 8 3}$ \\
\hline Total & $\mathbf{2 0}$ & $\mathbf{1 6}$ & $\mathbf{1 4}$ & & \\
\hline
\end{tabular}

The style of observations was as at Mutzschen, but because frequently more than one species occurred at different distances, some individuals were not identified to the species level. Unidentified individuals accounted for $20 \%$.

The weather during the observations at Mautitz was highly varied, with rapidly changing cloud cover (clouds types from cirrus to alto stratus to cumulus). During the observation days, the wind blew from different directions $-\mathrm{N}, \mathrm{NW}, \mathrm{W}, \mathrm{S}$ and $\mathrm{E}$. There were, however, hours with no wind. When the wind was blowing we noted its power by estimating the speed of the turbine rotors (the highest motions were 11 turns/ minute, but usually 3-6).

\section{RESULTS AND EVALUATION PROCEDURES}

All symbols of observation items (flights, circling and sitting) were transferred from the draft hand-made background maps to computer graphics (example Maps $3-4)$. Then the areas were divided into a few sub-areas that were suspected to be of different value for the observed birds (Maps 5-6). 


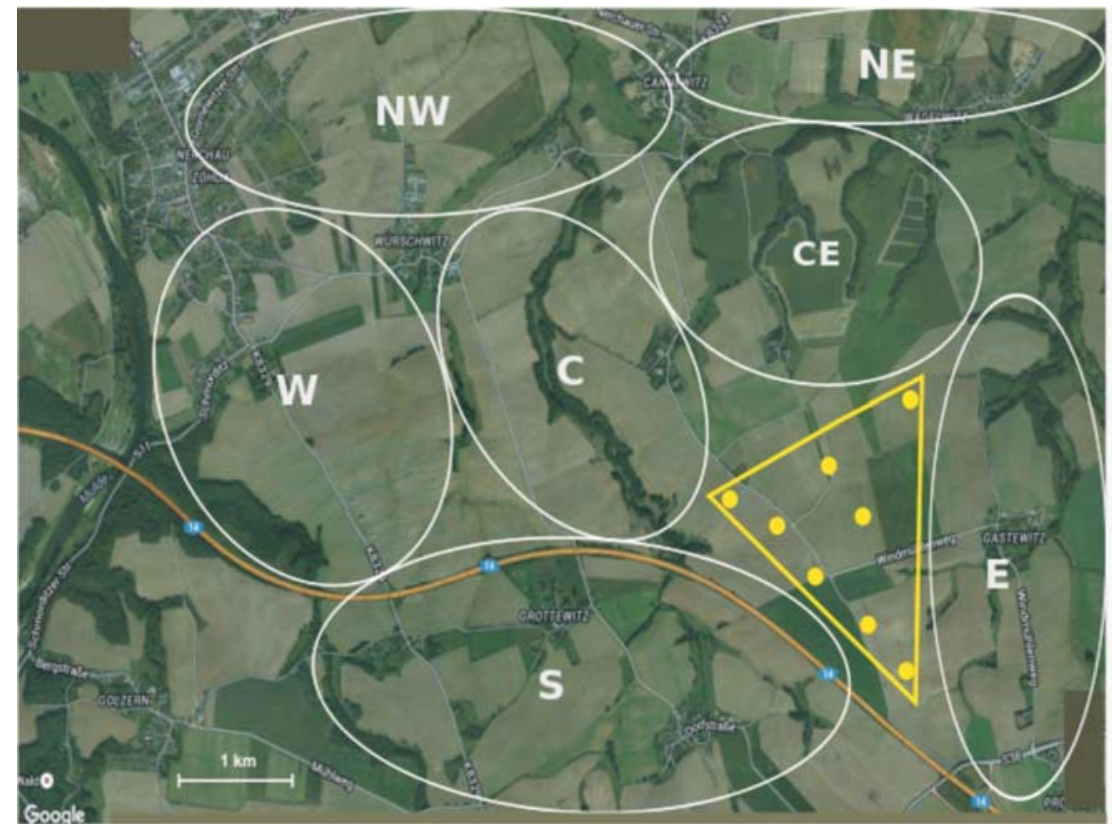

Map 5. Names of sub-areas at Mutzschen (in ellipses). Triangle and yellow dots - the area of the wind-farm with turbine locations.

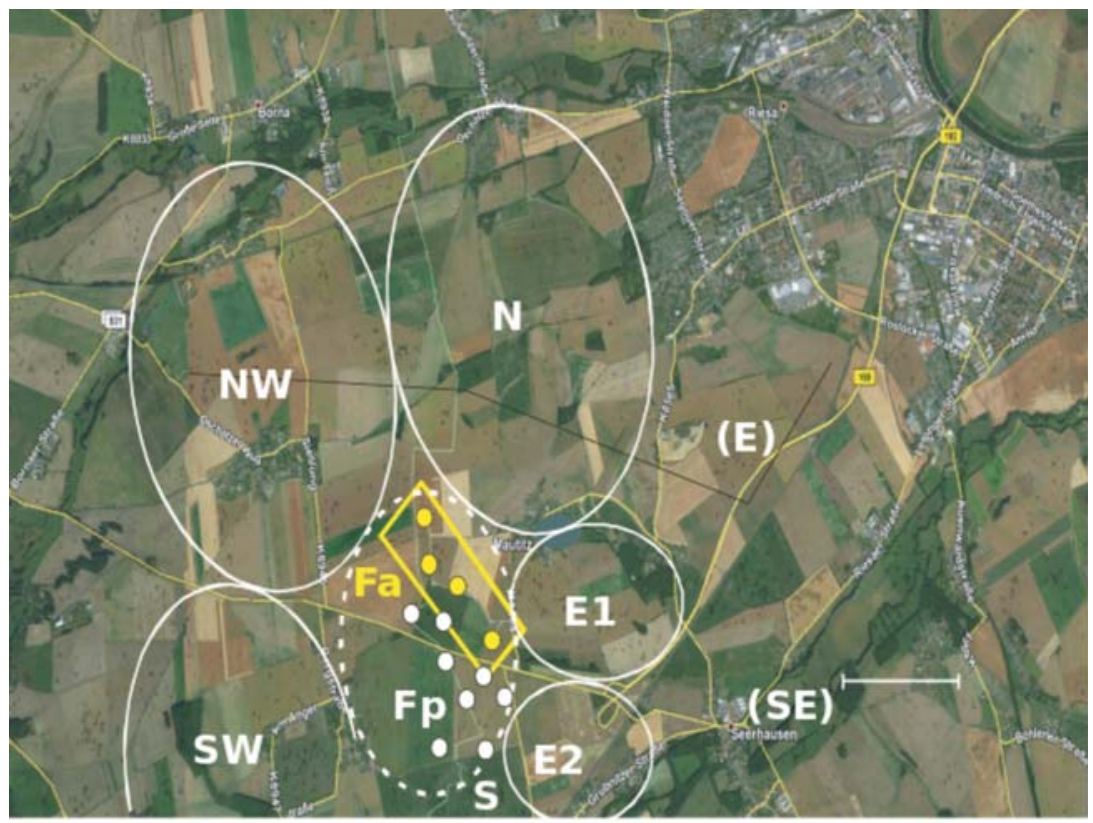

Map 6. Names of sub-areas at Mautitz. Rectangle, white and yellow dots - the area of the wind-farm with turbine locations (as on Map 2, Fa - actual wind farm, Fp - planned wind farm. 
At Mutzschen, sub-areas designated as NW and NE were situated along a wide valley running from Nerchau to the east. $\mathrm{W}$ is the area south of Nerchau, $\mathrm{C}$ the central area around the nest, from which birds can fly directly to the valley, CE is the area bordering with the central area that was used as a flyway in the direction of the $\mathrm{NE}$ area of the valley, area $\mathrm{S}$ was surprisingly rarely used by birds (perhaps because of the motorway?), and E was an area even less used than area S. Altogether there were 114 records of Red Kite individuals, on average 1.6 records per hour. For a better presentation of frequencies, each record was scored as to the time spent in the area: circling $=2$ units (long presence), flight $=1$ (if the bird at least partially crossed the area), occurrence close to the area $=0.5$. The frequency of occurrence units in different areas is listed in Table 3. This table also shows that the activity of birds was highly varied. Due to the short monitoring time and very wide variation in weather conditions, it is not possible to comment on the causes of this variation.

Table 3

Occurrence of items at sub-areas of Mutzschen wind farm

\begin{tabular}{|c|c|c|c|c|c|c|c|c|c|}
\hline Date & Farm & C & CE & E & S & W & NW & NE & Total \\
\hline 13 Jun. & $\mathbf{2 . 5}$ & 17.5 & 4.5 & 2 & 0 & 1 & 5.5 & 0 & $\mathbf{3 3 . 0}$ \\
\hline 14 Jun. & $\mathbf{0}$ & 12.5 & 0 & 0 & 0 & 2.5 & 19 & 0 & $\mathbf{3 4 . 0}$ \\
\hline 15 Jun. & $\mathbf{0}$ & 8 & 2 & 0 & 1 & 3 & 10 & 0 & $\mathbf{2 4 . 0}$ \\
\hline 16 Jun. & $\mathbf{0}$ & 2.5 & 7 & 0 & 0 & 5 & 12 & 8 & $\mathbf{3 4 . 5}$ \\
\hline 17 Jun. & $\mathbf{0}$ & 2 & 1 & 0 & 0 & 2 & 6 & 0 & $\mathbf{1 1 . 0}$ \\
\hline 18 Jun. & $\mathbf{0}$ & 5 & 1.5 & 0 & 0 & 0 & 8 & 5 & $\mathbf{1 9 . 5}$ \\
\hline 19 Jun. & $\mathbf{1}$ & 2.5 & 7 & 1 & 0 & 0 & 4 & 1 & $\mathbf{1 6 . 5}$ \\
\hline 20 Jun. & $\mathbf{2 . 5}$ & 15 & 11 & 2 & 5 & 5.5 & 2.5 & 1 & $\mathbf{4 4 . 5}$ \\
\hline Items & $\mathbf{6}$ & 65 & 34 & 5 & 6 & 19 & 67 & 15 & 217.0 \\
\hline \% & $\mathbf{2 . 8}$ & $\mathbf{3 0 . 0}$ & $\mathbf{1 5 . 7}$ & $\mathbf{2 . 3}$ & $\mathbf{2 . 8}$ & $\mathbf{8 . 8}$ & $\mathbf{3 0 . 9}$ & $\mathbf{6 . 9}$ & \\
\hline
\end{tabular}

The variations are presented in graphic form in Figure 1 (differences in the amount of the time spent in each area) and Figure 2 (numbers of records of Red Kites per day).

Combining daily maps into one map made it possible to indicate areas where birds occurred with different frequency (Map 7). The feeding grounds of the Red Kite pair clearly lie to the north of the nest, in the opposite direction to that of the wind farm. The valley area seems to be attractive to Red Kites, as single 'strange' individuals arrived from that direction (when three kites were observed simultaneously). During the entire monitoring time, a Red Kite flew through the farm area only four times (twice at the rotor level and twice well above the rotor level). All of these cases occurred when there was no motion of turbine rotors.

The area around the Mautitz wind farm was divided into several sub-areas that seemed to be of varying value for the observed birds (Map 6). Sub-areas $\boldsymbol{E} \mathbf{1}$ and $\boldsymbol{E} 2$ and the farm area $\boldsymbol{F}$ (Fa actual farm, $\boldsymbol{F} \boldsymbol{p}$ - planned farm) bordered directly on the nesting site. Sub-areas $\boldsymbol{S}, \boldsymbol{S W}, \boldsymbol{N W}$ and $\boldsymbol{N}$ were well controlled from the observation posts, while sub-areas $\boldsymbol{E}$ and $\boldsymbol{S} \boldsymbol{E}$ were too far for species identification - birds were visible as dots with $10 \times 50$ binoculars. 


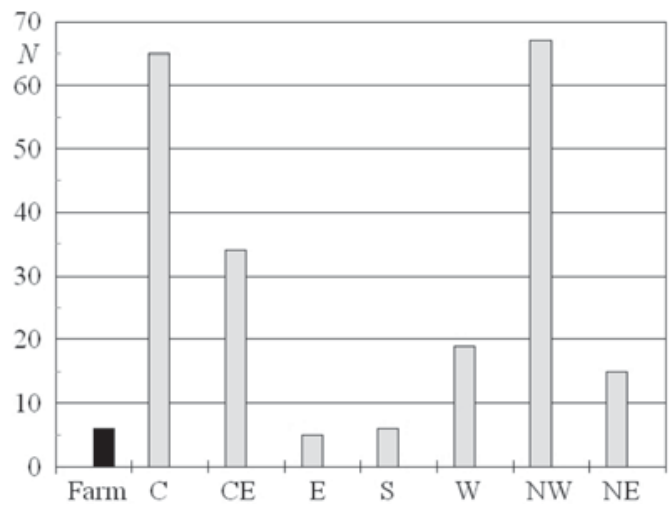

Fig. 1. Numbers of items per sub-area at Mutzschen (Red Kite)

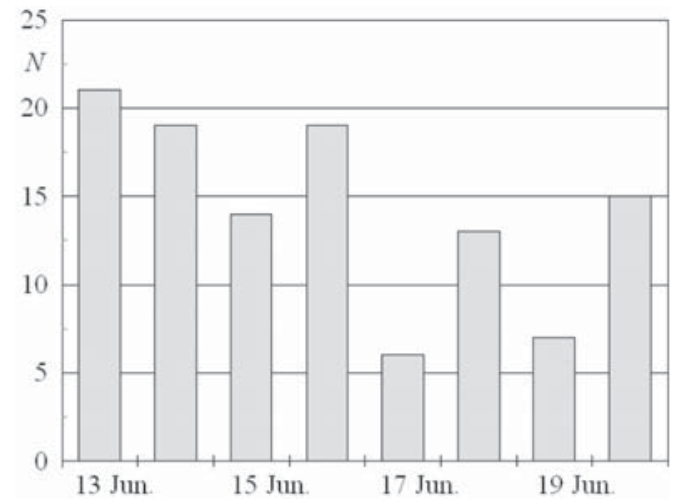

Fig. 2. Numbers of records per day at Mutzschen (Red Kite)

During the entire observation time a few bird species listed in Annex 1 of Directive 2009/147/EC were observed: Red Kite Milvus milvus, Black Kite Milvus migrans, Marsh Harrier Circus aeruginosus, Hen/Montagu's Harrier Circus cyaneus/pygargus, and White Stork Ciconia ciconia. The most numerous were Red Kite, Black Kite and Marsh Harrier - discussed below in more detail, while Hen/Montangu's Harrier was observed once (a male), and there was one observation of five White Storks near a harvesting machine.

Altogether there were 235 records of kites, on average 3.45 records per hour. On 20-24 July there were 151 records of identified individuals, and the ratio of numbers of Red Kite to Black Kite was 1:1.32. If we assume equal identifiability of species and the presence of four adults in the area, we can estimate that there were three young Red Kites and four young Black Kites. This is in agreement with the information that there were three chicks in the Red Kite nest, obtained from a local observer. The second most common raptor species among those in Annex I of the Directive was the Marsh Harrier, with 37 records (both males and female/young individuals were observed) and none was observed crossing the wind farm area. The most common species, frequently observed all around the area, was Kestrel Falco tinnunculus. Another common raptor species was Common Buzzard Buteo buteo, which was observed spo- 
radically during the first five days, but on the last two days in numbers up to 5-6 individuals together; this was probably a family or families that had migrated from neighbouring area.

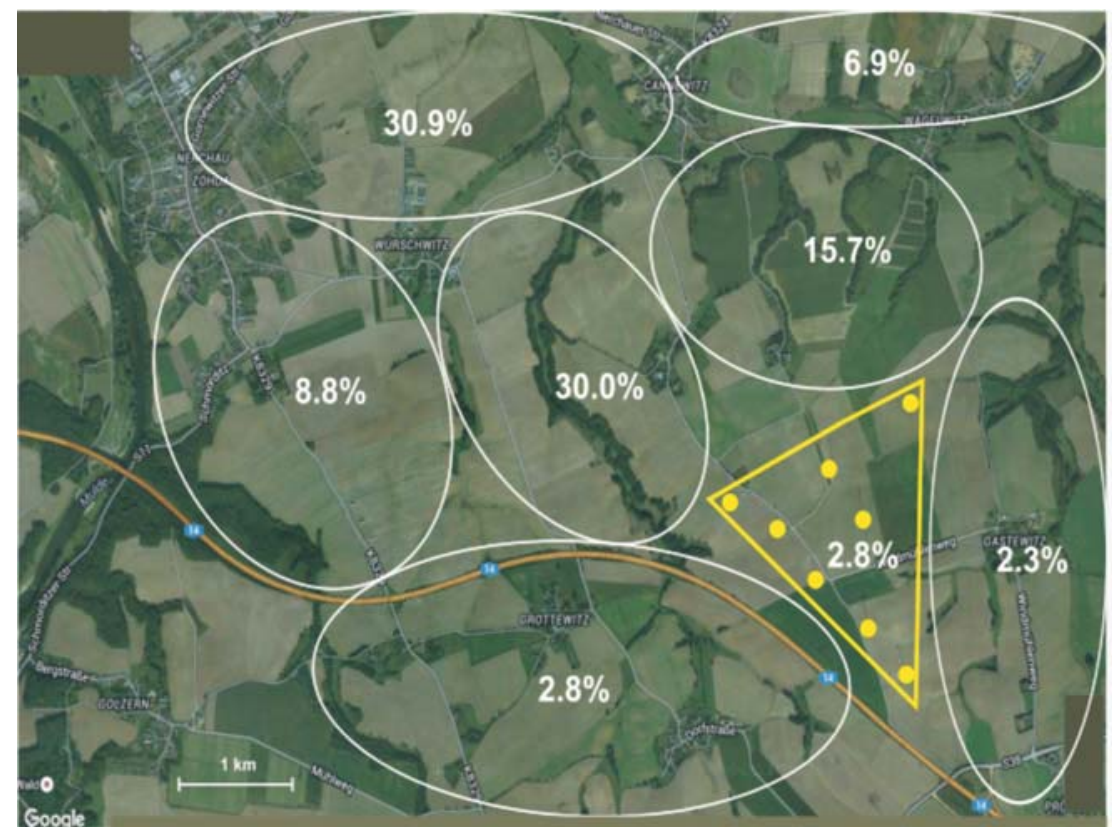

Map 7. Distribution of Red Kite activity items in sub-areas at Mutzschen (see Map 5)

For a better presentation of frequencies of occurrence of birds in different parts of the area, each record was scored as to time spent in the area, the same way as for Mutzschen: circling $=2$ units (long-time occurrence), flight $=1$ (if the bird at least partially crossed the area). The frequency of occurrence units in different areas is listed in Table 4. This table also shows that the activity of birds was quite varied. Due to the short monitoring time and very wide variation in weather conditions, it is not possible to comment on the causes of this variation. The variation is presented in graphic form in Figure 3 (differences in the amount of time spent in each area by individuals of different species). It can be seen here that the distribution of species' preferred areas is varied. Even for kites, distributions are statistically significantly different (chi-square test, $d f=6, p<0.01$ ). Combining daily species maps into one made it possible to indicate areas where birds occurred with different frequency (Maps 8-10). The maps visualize these differences: the Red Kite preferred more distant hunting grounds (NE sub-area), while the Black Kite adhered to the sub-area closest to the nest (E1). This tendency was visible even in the portion of individuals visiting the current farm area and the area to be built up with more turbines: only $2.8 \%$ of the Red Kite records were at the current farm area (3 flights through the line of turbines, usually close to the midpoint between the turbines, at varying heights, and when rotor speed was up to 5 turns/min); the percentage of Black Kite individuals crossing the 
line of turbines was three times higher (9.9\%). It can generally be expected that these percentages, in relation to the area of the farm, will be at the same level when the farm has been expanded. The Marsh Harriers observed arrived mainly from the north (north-east) from an unknown breeding site.

Table 4

Distribution of observation items among sub-areas of Mautitz wind farm

\begin{tabular}{|c|c|c|c|c|c|c|c|c|c|}
\hline & \multicolumn{2}{|c|}{ Farm } & \multirow{2}{*}{$S$} & \multirow{2}{*}{ SW } & \multirow{2}{*}{ NW } & \multirow{2}{*}{$\mathrm{N}$} & \multirow{2}{*}{ E1 } & \multirow{2}{*}{ E2 } & \multirow{2}{*}{ Total } \\
\hline & Actual & Planned & & & & & & & \\
\hline \multicolumn{10}{|c|}{ Kites* } \\
\hline Items & 0 & 5 & $\mathbf{0}$ & 1 & 5 & 32 & 18 & $\mathbf{0}$ & 61 \\
\hline$\%$ & 0.0 & 8.2 & 0.0 & 1.6 & 8.2 & 52.5 & 29.5 & 0.0 & \\
\hline \multicolumn{10}{|c|}{ Red Kite } \\
\hline Items & 3 & 6 & $\mathbf{0}$ & $\mathbf{0}$ & 17 & 54 & 26 & 3 & 109 \\
\hline$\%$ & 2.8 & 5.5 & 0.0 & 0.0 & 15.6 & 49.5 & 23.9 & 2.8 & \\
\hline 20 July & 0 & 0 & 0 & 0 & 3 & 17 & 7 & 0 & 27 \\
\hline 21 July & 0 & 0 & 0 & 0 & 0 & 2 & 1 & 0 & 3 \\
\hline 22 July & 1 & 2 & 0 & 0 & 3 & 19 & 2 & 0 & 26 \\
\hline 23 July & 1 & 3 & 0 & 0 & 6 & 9 & 7 & 3 & 28 \\
\hline 24 July & 1 & 1 & 0 & 0 & 5 & 7 & 9 & 0 & 22 \\
\hline \multicolumn{10}{|c|}{ Black Kite } \\
\hline Items & 17 & 23 & 0 & 4 & 17 & 40 & 57 & 13 & 171 \\
\hline$\%$ & 9.9 & 13.5 & 0.0 & 2.3 & 9.9 & 23.4 & 33.3 & 7.6 & \\
\hline 20 July & 0 & 2 & 0 & 0 & 3 & 18 & 7 & 2 & 32 \\
\hline 21 July & 3 & 4 & 0 & 1 & 2 & 0 & 4 & 1 & 12 \\
\hline 22 July & 1 & 4 & 0 & 2 & 5 & 17 & 16 & 2 & 46 \\
\hline 23 July & 4 & 4 & 0 & 1 & 5 & 4 & 10 & 3 & 27 \\
\hline 24 July & 9 & 9 & 0 & 0 & 2 & 1 & 20 & 5 & 37 \\
\hline \multicolumn{10}{|c|}{ Marsh Harrier** } \\
\hline Items & 6 & 7 & $\mathbf{0}$ & 1 & 12 & 16 & 8 & $\mathbf{0}$ & 50 \\
\hline$\%$ & 12.0 & 14.0 & 0.0 & 2.0 & 24.0 & 32.0 & 16.0 & 0.0 & \\
\hline
\end{tabular}

* 18-19 July, ** 18-24 July; numbers for Actual Farm are the parts inside "Planned Farm" numbers

\section{DISCUSSION}

There is general agreement that the Red Kite is more susceptible to collision risk than the Black Kite. A number of analyses of the risk of collision of raptor birds with wind turbines stress that several local constraints influence the level of risk. The authors list the usual height of flights for a given species as one of the important constraints (e.g. Hötker et al. 2006). For a few species (especially harriers), the usual flight height during hunting puts these species at a lower risk than others. For an example, harriers usually fly below the most common lowest height of turbine rotors; Schaub et al. 2017 list percentages of low flights among all observed flights for Montagu's, Hen and Marsh harriers in Western Europe as 86\%, 85\% and 95\%, respectively, while Busse (2013) reported values for Poland of $84.0 \%, 94.5 \%$ and $92.1 \%$. 


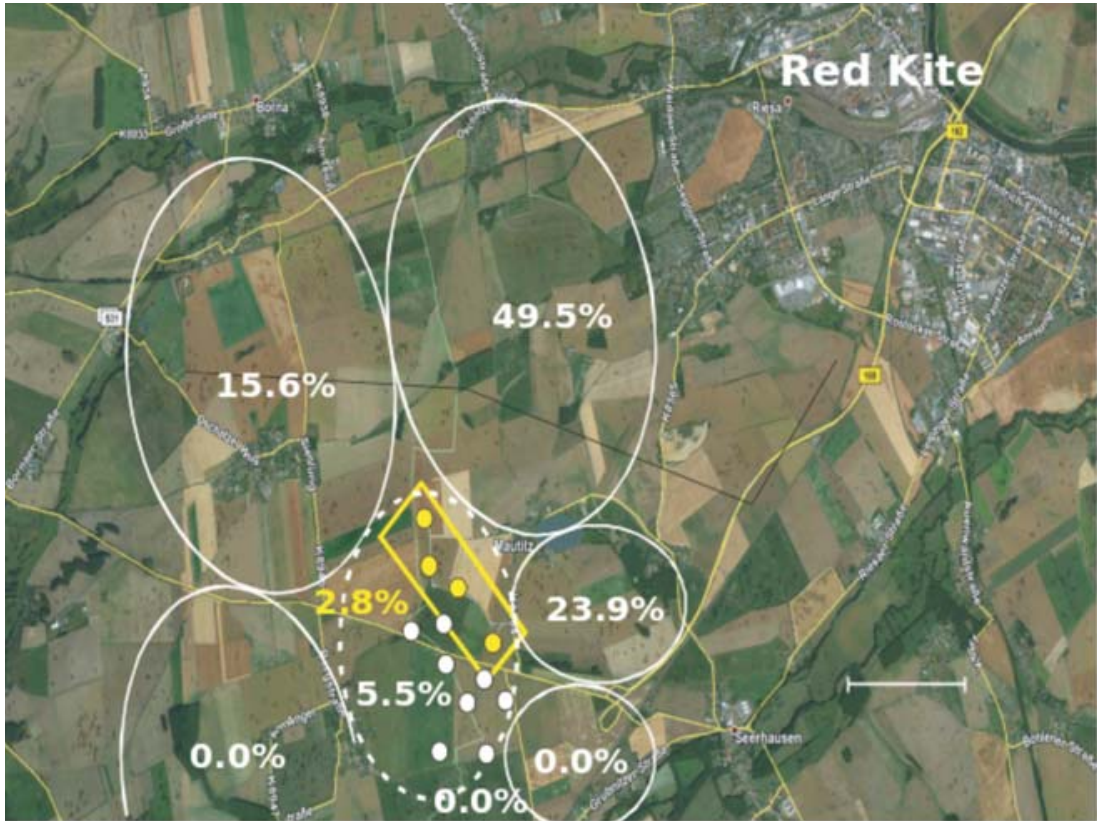

Map 8. Distribution of Red Kite activity items in sub-areas at Mautitz (see Map 6)

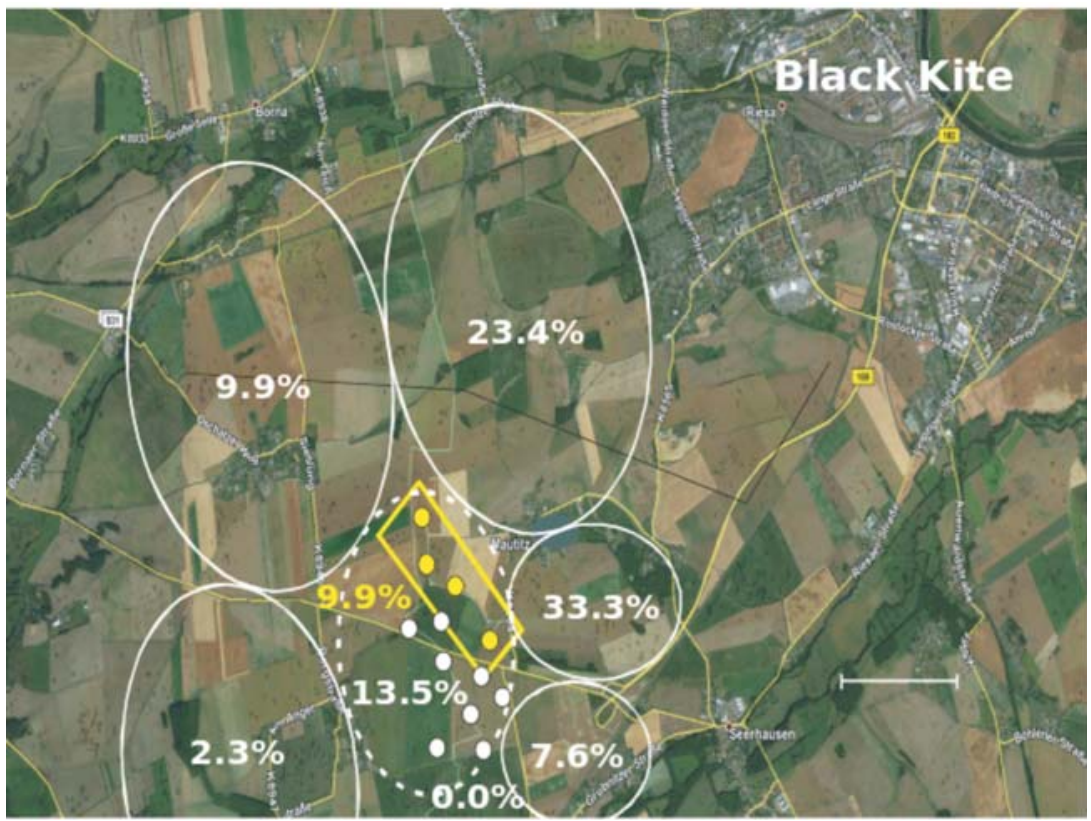

Map 9. Distribution of Black Kite activity items in sub-areas at Mautitz (see Map 6) 


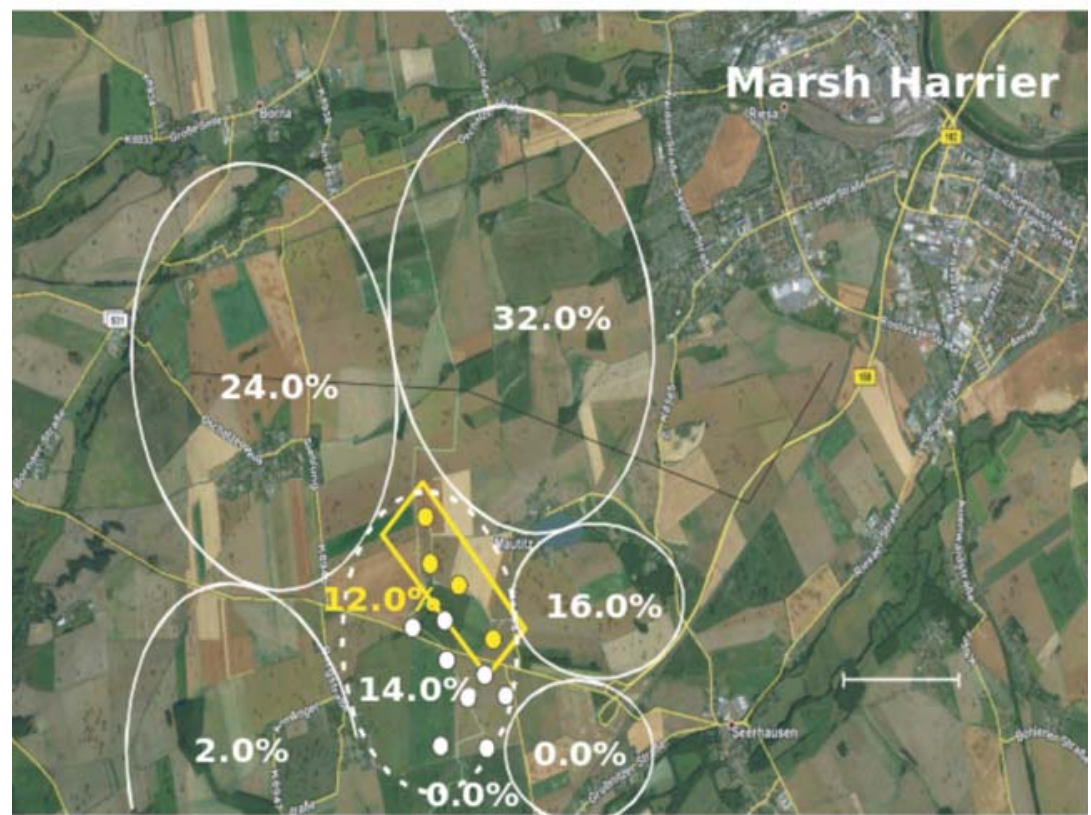

Map 10. Distribution of Marsh Harrier activity items in sub-areas at Mautitz (see Map 6)

For the Red Kite, Busse (op. cit.) gave this value as 59.1\%, thus indicating a potentially higher collision risk for this species: he estimated the collision risk for this species as 0.0075/turbine/year (once per 133 years), as compared to 0.0012 (once per 814 years) for the Black Kite. According to Hötker et al. (2006), this parameter can be estimated for Red Kite as 0.006/turbine/year, while Dürr (2009) reported this value as 0.028. Eichhorn et al. (2012) built a sophisticated model for estimating the collision risk of predatory birds. They claimed that 'collision risk declines exponentially with increasing distance between a bird's aerie and WT [wind turbine]' and that this relation is modified by the avoidance rate for the species. The first element is obvious, as in a two-dimensional space, if we assume random movements of birds from the eyrie, the frequency of observations of birds at growing distances will be according to a fixed relation of $N$ flights to the square of the distance $\left(N /\right.$ dist $\left.^{2}{ }^{2}\right)$. Estimations are improved by correction of the collision probability by the avoidance rate. Additionally, the authors use Hötker's and Dürr's (op. cit.) data to estimate the distance from kite eyries to wind farms, and citing Nachtingall (2008), claim that the results are positive proof of the model: 'The derived impact function is therefore, indirectly validated.' However, the distance values from Hötker (2000-2500 m) and from Dürr (1300-1500 m) are very different and, much more importantly, these authors overlooked the fact that Nachtigall (op. cit.) showed in his Fig. 3-3 that flights of adults from nests are highly asymmetrical, and thus the model based on the assumption of accidental distribution of flight directions is not applicable for the species. The results of our observations confirm Nachtigall's finding (op. cit.) that the flights of both kite species are 
not at all random (the birds clearly prefer some directions and abandon others). From observations performed when the nests were close to the wind farms, it is not possible to conclude whether this selectivity of flight directions at the study sites is caused by high avoidance of the farm or by independent properties of the surrounding terrain. High agreement of our results with the data presented by Nachtigall (2008) may support the hypothesis that natural causes of this phenomenon play an important role in the picture obtained.
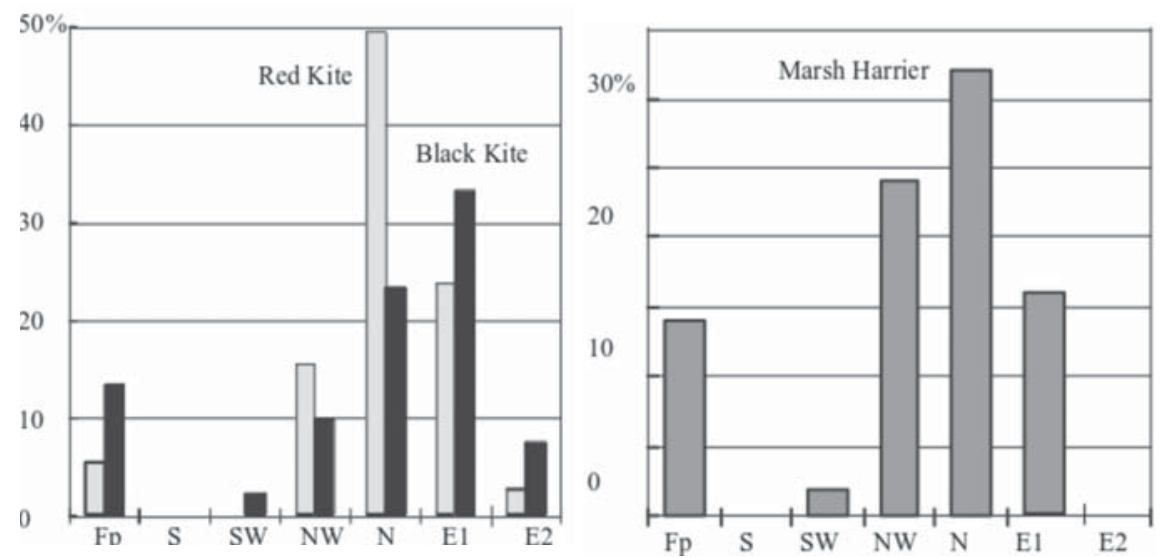

Fig. 3. Shares of items per sub-area at Mautitz (Red Kite, Black Kite and Marsh Harrier)

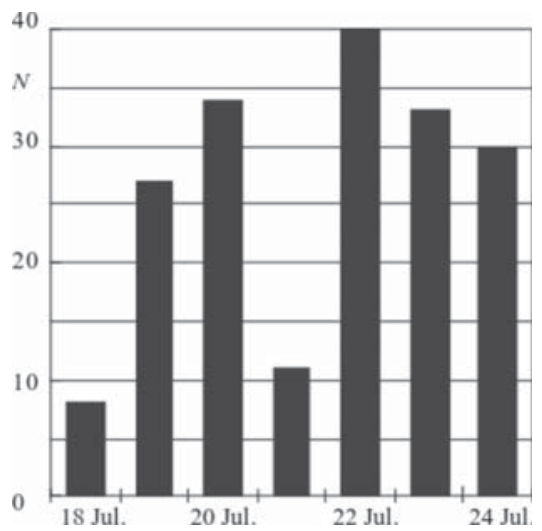

Fig. 4. Numbers of records per day at Mautitz (Red Kite + Black Kite + Marsh Harrier)

\section{CONCLUSIONS}

1. The distribution of flights of adult Red Kites in the vicinity of the Mutzschen wind farm during chick-feeding time is not random, as the flights are clearly concentrated on specific target hunting areas, while other directions are visited infrequently. The directions of kite flights at Mautitz in the period just after the young birds have left the nest are still clearly selective - the birds favour some areas, while abandoning 
others. Thus, the local constraints of the area and specific hunting habitat preferences seem to have a strong influence on the local patterns of flight behaviour and, consequently, on local collision probability.

2. Based on point 1 above, it may be advisable to conduct special monitoring of movement patterns at breeding time if kite nests are found close to the planned location of the wind farm.

3. Kites crossed both farms very infrequently, and this was observed only when the turbine rotors were not in motion or were turning slowly (below 5 turns/min.).

\section{REFERENCES}

Band W., Madders M., Whitfield D.P. 2007. Developing field and analytical methods to assess avian collision risk at wind farms. In: Birds and wind farms. Risk assessment and mitigation. Edit Quercus, Madrid.

Busse P. 2013. Methodological procedure for pre-investment wind farm ornithological monitoring based on collision risk estimation. Ring 35: 3-10.

Eichhorn M., Johst K., Seppelt R., Drechsler M. 2012. Model-Based Estimation of Collision Risks of Predatory Birds with Wind Turbines. Ecology and Society 17 (2): 1. http://dx.doi.org/10.5751/ ES-04594-170201

Hötker H., Thomsen K.M., Jeromin H. 2006. Impacts on biodiversity of exploitation of renevable energy sources: the example of birds and bats. Edit NABU.

LAG VSW (Länderarbeitsgemeinschaft der Vogelschutzwarten). 2014. Abstandsempfelungen für Windenergieanlagen zu bedeutsamen Vogellebensräumen sowie Brutplätzen ausgewähter Vogelarten (Stand April 2015). Berichte zum Vogelschutz 51: 16-42.

Percival S.M. 2007. Predicting the effects of wind farms on birds in UK: the development of an objective assessment method. In: Birds and wind farms. Risk assessment and mitigation. Edit Quercus, Madrid.

Schaub T., Klaassen R.H.G., Bouten W., Schlaich A.E., Ben K.J. 2017. EOU 2017. Abstracts.

Scottish Natural Heritage. 2011. Use of Avoidance Rates in the SNH Wind Farm Collosion Risk Model. http://www.snh.gov.uk/docs/A305435.pdf

Smales I. 2006. Impacts of avian collisions with wind power turbines: an overview of the modelling of cumulative risks posed by multiple wind farms. BIOSIS Research Report. 


\section{Short guidelines to preparing manuscripts to THE RING}

Full guidelines information see www.wbwp-fund.eu/ring

\section{Terms of submission}

THE RING considers for publication original research that has not been published previously (except in the form of an abstract or as part of a published lecture or academic thesis). Submission to the Ring implies that this is the case and that the submitted manuscript is not under consideration for publication elsewhere.

During the submission process, authors are asked to declare that the manuscript has been seen and approved by all authors. Submission also implies that authors agree to abide by THE RING's editorial policies and publishing ethics, including the declaration of any competing interests to the journal on submission of a manuscript.

Authors should clearly highlight the key finding(s) of the paper and explain its significance and interest to the field in their cover letter.

As THE RING is published in an Open Source regime by VERSITA, authors are obliged to sign "Licence to publish". Adequate declarations are available at the journal web site www.wbwp-fund.eu/ring and need to be signed and delivered with the manuscript - "Licence to publish" at last in a moment of accepting for publication.

Upon article acceptance, most Research Articles are posted on the journal website as accepted author manuscripts ("Early Bird") prior to journal copyediting and layout and in advance of publication of the print and online issues in which they will subsequently appear. Authors who would prefer their accepted author manuscript NOT to be posted as an Early Bird Article should include this information in their cover letter.

The on-line version of the journal is a primary one to the printed edition.

\section{Manuscript preparation}

\section{Front page}

It should contain title, author(s) name with full given name(s), abstract, a few key words, institutional affiliation of the author(s) and address(es) for correspondence (with an e-mail if appropriate). The abstract (up to 200 words) should summarise methods applied and results of work. It should be informative in itself without reference to other parts of the paper.

\section{Text}

The text should be written clearly and concisely and complicated idioms and jargon avoided. Authors using statistical analysis must provide essential details of the statistical methods applied and basic assumptions. Only the most commonly used statistics and tests could be mentioned by their names alone. Illustrations and tables should be clear, self-explaining (as much as possible), without unnecessary details. Summary - limited to $20 \%$ of the text volume - is not obligatory.

English names of species should begin with capital letters. Their Latin equivalents should be given (a) with the first usage (in the title, text or explanation to figures) and (b) in abstract if not given in the title. In tables use only Latin names. All Latin names must be given in Italics. Subheads in the text should not be numbered. Hierarchically complicated subdivisions may be indicated on the margin of a hardcopy.

Metric units and the following date format, e.g. 1990-1999, 1 August 1989, 1 Aug. (in tables and figures) should be used. Spaces should be used between numerical values and abbreviations, e.g. "3 p/ 10 ha", "pp. 4-7".

References should be made using "an author and a year" system, e.g. “...after Audrey (1989)...", “...(Taczanowski 1882)...", “...(Rydzewski 1935, Czarnecki 1979)...”, “...the problem was discussed by many authors (Bardy 1983; Aller and Crown 1984, 1991; Carry et al. 1987)...". Note format for two and more authors of cited paper as well as the sequence of authors cited according to the years of their first paper in the last example. Papers in press could be cited as in press, and listed in References, if they have been formally accepted for publication. Unpublished data (personal communication - pers. comm., in letter - in litt., unpubl.) can be cited in the text only (not in References).

The list of references should be given in an alphabetical order according to the format shown as examples for supplement to the journal, journal full title, journal abbreviation, book, chapter:

Berthold P. 1973. Proposals for the standardisation of the presentation of data of animal events, especially migratory data. Auspicium, Suppl.: 49-57.

Branson N.J.B.A., Minton C.D.T. 1976. Moult, Measurements and Migrations of the Grey Plover. Bird Study 23, 4: 257-266.

Busse P., Kania W. 1970. Operation Baltic 1961-1967. Working methods. Acta orn. 12: 231-267.

Cramp S., Simmons K.E.L. (Eds). 1983. Handbook of the Birds of Europe, the Middle East and North Africa. The Birds of the Western Palearctic. vol. 2. Oxford Univ. Press, Oxford.

Pinowski J., Zając R. 1990. Damages to crops caused by birds in Central Europe. In: Pinowski J., Summers-Smith J.D. (Eds). Granivorous birds in the agricultural landscape. Warszawa: pp. 333-347. 
Guidelines... continued

Papers published in English, French or German or with an original title of the summary in these languages should be cited as they are. English translation of the title from other languages should be given in a square bracket. Title, not translated, written originally in non-Latin script must be transcribed according to ISO rules. Titles of journals should be abbreviated as in the World List of Scientific Periodicals. If abbreviation is not known, full journal name must be given.

\section{Marmat}

Manuscript, including tables and graphics, should be delivered in an electronic form in PC compatible format. Any commonly used file format is acceptable but Microsoft (.doc/.xls) and Open Source (.odt/.ods) formats are preferred as the text/spreadsheet formats.

The tables (with titles or headings) and figure captions should be prepared on separate sheets and in their own files (do not include them into the text file). Tables larger than the usual page size of the journal should be avoided. Tables and figures must be mentioned in the text and numbered (separately) with Arabic numerals in a format: “...are shown in Figure 3.”, “... (Fig. 3).”.

Computer graphics should be used as figures, if possible, and delivered as separate files, not embedded into the text file. Graph files must be supplemented by the original data in ASCII or spreadsheet format. Other illustrations should be submitted as bitmap files (preferably in .jpg or .png format in resolution 300 dpi or more) or as a hard copy not exceeding A4 paper size and by its quality must allow direct scanning. Their layout and the size of the inscriptions should be adapted to the expected final size.

One set of galley proofs will be sent to author for correction. They should be returned as soon as possible. As extensive alterations at the proof stage delay publication, they will be accepted only under exceptional circumstances (e.g. substantial errors found).

\section{CONTENTS}

Przemysław Busse

BUSSE'S FLAT ORIENTATION CAGE VS. EMLEN'S FUNNEL - COMPATIBILITY,

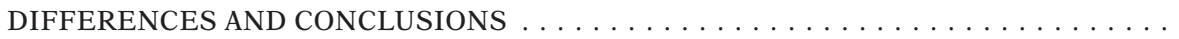

József Gyurácz, Péter Bánhidi, József Góczán, Péter Illés, Sándor Kalmár,

Péter Koszorús, Zoltán Lukács, Csaba Németh, László Varga

BIRD NUMBER DYNAMICS DURING THE POST-BREEDING PERIOD

AT THE TÖMÖRD BIRD RINGING STATION, WESTERN HUNGARY . . . . . . . . . . . .

Simon I. Awad, Michael H. Farhoud and Riad K. Abu Saada LONG-TERM BIRD RINGING IN PALESTINE . . . . . . . . . . . . . . . .

Shiladitya Mukhopadhyay and Subhendu Mazumdar COMPOSITION, DIVERSITY AND FORAGING GUILDS OF AVIFAUNA

IN A SUBURBAN AREA OF SOUTHERN WEST BENGAL, INDIA. .

Przemysław Busse and Izabella Rząd SOME DATA ON THE BEHAVIOUR OF KITES (MILVUS MILVUS, MILVUS MIGRANS) NESTING CLOSE TO TWO ACTIVE WIND FARMS

IN SAXONY, GERMANY 